\title{
Pregnancy-specific protein B and progesterone concentrations in relation to nutritional regimen, placental mass and pregnancy outcome in growing adolescent ewes carrying singleton fetuses
}

\author{
J. M. Wallace ${ }^{1}$, R. P. Aitken ${ }^{1}$, M. A. Cheyne ${ }^{1}$ and P. Humblot ${ }^{2}$ \\ ${ }^{1}$ Rowett Research Institute, Bucksburn, Aberdeen, AB21 9SB, UK; and ${ }^{2}$ UNCEIA, Services Techniques, \\ 13 rue Jouet, BP65, 94703 Maisons Alfort, France
}

\begin{abstract}
The objective of this study was to investigate whether peripheral plasma profiles of pregnancy specific protein B (PSPB) are predictive of pregnancy outcome in adolescent sheep in which growth of the placenta has been compromised by the competing nutrient demands of maternal tissue synthesis. Embryos recovered on day 4 after oestrus from adult ewes inseminated by a single sire were transferred in singleton to prepubertal adolescent recipients. After transfer, the adolescent recipients were individually offered a high or low proportion of a complete diet to promote rapid (RMG) or normal (NMG) maternal growth rates ( $n=12$ per group). After day 100 of gestation the feed intake of the NMG group was adjusted weekly to meet the nutrient requirements of the gravid uterus. Blood was sampled three times a week throughout gestation and analysed for PSPB and progesterone. Liveweight gain during the first 120 days of gestation was $229 \pm 9.1$ and $105 \pm 3.9 \mathrm{~g} \mathrm{day}^{-1}$ for the RMG and NMG groups, respectively. For ewes delivering live young, mean placental mass at term was $263 \pm 16.8$ and $438 \pm 44.6 \mathrm{~g}(P<0.002)$, while lamb birthweight was $2.74 \pm 0.25$ and $4.34 \pm 0.27 \mathrm{~kg}(P<0.001)$ for the RMG $(n=8)$ and NMG $(n=11)$ groups, respectively. The biphasic pattern of PSPB secretion during gestation was similar in all ewes delivering live young, but individual concentrations within treatment groups were highly variable. Mean PSPB concentrations were lower in RMG than in NMG ewes throughout gestation $(P<0.05)$ and the major differences in relative terms were detected between days 50 and 100 of pregnancy. PSPB concentrations during this latter period were correlated $(P<0.05)$ with placental mass at term but not with lamb birthweight. High dietary intakes, leading to rapid maternal growth rates were associated with low peripheral progesterone concentrations $(P<0.02)$ throughout gestation. Irrespective of treatment group, progesterone concentrations during the second half of pregnancy were positively associated with both placental mass at term $(P<0.002)$ and lamb birthweight $(P<0.01)$. The incidence of non-infectious abortion during late gestation (125 \pm 1.3 days) was higher $(P<0.001)$ in the RMG (4 of 12$)$ than in the NMG ( 1 of 12$)$ group and was associated with abnormal PSPB profiles in the former group. The mass of the fetus at the time of abortion was highly correlated $(P<0.01)$ with mean PSPB concentrations up to day 120 of gestation, but was independent of peripheral progesterone concentrations. These results suggest that sequential measurement of PSPB may provide a reliable indicator of fetal distress and adverse pregnancy outcome in singleton bearing ewes. PSPB and progesterone analysis may also have prognostic value as a biochemical marker of suboptimal placental growth and function in sheep.
\end{abstract}

\section{Introduction}

Hormones of placental and fetal origin are considered to be more reliable biochemical markers of pregnancy status and fetal wellbeing than are maternally derived hormones, such as progesterone, which are not pregnancy-specific. The binucleate

Received 8 July 1996. cells of the ruminant placenta secrete several pregnancy-specific proteins including placental lactogen (Lee et al., 1986), pregnancy-specific protein B (PSPB; Reimers et al., 1985) and pregnancy-associated glycoprotein (PAG; Zoli et al., 1992). Pregnancy-specific protein $B$ can be detected readily in the maternal peripheral circulation from the time of initial placentome formation and has been widely used to diagnose pregnancy in a variety of ruminants (Sasser et al., 1986; Wood 
et al., 1986; Humblot et al., 1990; Ruder et al., 1988). Although the biological function of PSPB is not known, its localized expression in the fetal binucleate cells that encroach most invasively into the maternal caruncular epithelium suggests that it may be a useful marker of placental development and function. Profiles of PSPB have been characterized in cows with induced (Semambo et al., 1992) and spontaneous abortions (Dobson et al., 1993) and have been used to diagnose the incidence of embryonic mortality during the first trimester of pregnancy (Humblot et al., 1988; Vasques et al., 1995). Concentrations of PSPB are higher during twin versus singleton pregnancies in sheep (Willard et al., 1995), goats (Humblot et al., 1990) and cows (Patel et al., 1995; Vasques et al., 1995), but none of these studies has examined PSPB concentrations in relation to placental mass.

In a recent study of nutrient partitioning in pregnant adolescent sheep, we reported that rapid maternal growth rates during pregnancy were associated with a high incidence of spontaneous abortion and a major reduction in both placental and fetal mass at term compared with normally growing adolescent dams (Wallace et al., 1996). We have now investigated PSPB and progesterone secretion in relation to placental mass and pregnancy outcome in these adolescent sheep to determine whether PSPB measurement is a reliable indicator of fetal-placental function in this model.

\section{Materials and Methods}

\section{Animals and experimental design}

Embryos from superovulated adult ewes, inseminated by a single sire were recovered on day 4 after oestrus and transferred synchronously in singleton into the uterus of 24 recipient ewe lambs as described by Wallace et al. (1996). The recipient ewe lambs were prepubertal, $148 \pm 2.3$ days old and weighed $44.4 \pm 0.6 \mathrm{~kg}$ at the time of ovulation induction. After embryo transfer, recipient ewe lambs were allocated to one of two dietary treatments on the basis of liveweight, age and ovulation rate at the time of transfer. The recipients were housed in individual pens and offered either a high or low proportion of a complete diet calculated to promote rapid (RMG) or normal maternal growth rates (NMG, $n=12$ ewes per group). The aim of the latter group was to maintain a moderate growth rate of approximately $75 \mathrm{~g} \mathrm{day}^{-1}$ during the first 100 days of gestation. The diet supplied 10.2 MJ metabolizable energy and $137 \mathrm{~g}$ crude protein $\mathrm{kg}^{-1}$ and was offered in two equal feeds at 08:00 h and 16:00 h daily. The amount of feed offered to high intake recipients was increased gradually over 2 weeks until the amount of the daily feed refusal was approximately $15 \%$ of the total offered, equivalent to ad libitum intakes. The amount of feed offered was reviewed, and adjusted on an individual basis when appropriate, three times a week on the basis of weight change data (recorded weekly) and the amount of feed refused. After day 100 of gestation the feed intake of the NMG ewes was adjusted weekly to maintain body condition score (based on the criteria of Russel et al., 1969) and meet the increasing nutrient demands of the developing fetus.

\section{Pregnancy outcome}

Five ewes aborted spontaneously during the final month of gestation. The aborted fetus was weighed and the gross appearance recorded. Fetal and placental tissues and maternal serum samples (collected on the day of physical abortion and 2 weeks later) were negative for Toxoplasma gondii, Chlamydia psittaci and border disease. Pregnancy outcome was determined in the remaining ewes $(8 \times \mathrm{RMG}$ and $11 \times \mathrm{NMG})$ at term. Lamb birthweight was recorded immediately after parturition, before the first suckling episode. After the placenta was delivered it was washed, blotted and weighed. The fetal cotyledons were dissected and counted and their total mass recorded.

\section{Blood sampling and radioimmunoassays}

Blood samples were collected by jugular venepuncture at 10:00 h, three times a week (Monday, Wednesday and Friday) throughout gestation and analysed for PSPB and progesterone. Concentrations of PSPB were measured in duplicate by radioimmunoassay as described by Humblot et al. (1990). The interand intra-assay coefficients of variation were $15 \%$ and $10 \%$, respectively, and the limit of detection was $0.2 \mathrm{ng} \mathrm{ml}^{-1}$. Progesterone concentrations were measured in $100 \mu \mathrm{l}$ aliquots of plasma after extraction and radioimmunoassay as described by Djahanbahkch et al. (1981). The inter- and intra-assay coefficients of variation were $17.8 \%$ and $10.1 \%$, respectively; the detection limit was $0.3 \mathrm{ng} \mathrm{m}^{-1}$ and the recovery of progesterone from plasma was $68.2 \pm 1.8 \%$. Values were adjusted to take into account extraction losses.

\section{Statistical analyses}

The physical data were analysed using Student's t test and chi squared where appropriate. Correlation analysis was by Pearson's product moment test. The distribution of PSPB values was heavily skewed and the standard deviations were proportional to the means so most of the analyses were performed on log-transformed data. The data for each sampling day were treated as separate variables and the whole set was subjected to a principal components analysis. As the first principle component explained most of the variability and no other component explained more than 10\%, the first latent variable was used to test for differences between groups using a standard $t$ test. In addition, the individual mean PSPB concentrations were calculated for days 18-49, 50-101 and 102-145 of gestation and the overall treatment means compared by $t$ test. A similar analysis was performed on individual mean progesterone concentrations between day 5 and day 70 , and day 73 and day 135 of gestation.

\section{Results}

\section{Liveweight changes and pregnancy outcome}

The dietary-induced changes in maternal weight and body condition score during pregnancy for adolescent recipient ewes are presented (Table 1). Maternal liveweight was significantly 
Table 1. Dietary-induced changes in maternal weight and body condition score during pregnancy for rapidly growing (RMG) versus normally growing (NMG) adolescent ewes

\begin{tabular}{lccc}
\hline Parameter & RMG & NMG & $\begin{array}{c}\text { Significance } \\
\text { of differences }\end{array}$ \\
\hline Number of adolescents & 12 & 12 & \\
Liveweight at & & & $n$ \\
$\quad$ Embryo transfer & $44.3 \pm 0.89$ & $44.5 \pm 0.87$ & $* * *$ \\
Day 35 of gestation & $52.0 \pm 1.03$ & $46.0 \pm 0.75$ & $* * *$ \\
Day 95 of gestation & $66.5 \pm 1.03$ & $51.8 \pm 1.14$ & $* * *$ \\
Day 120 of gestation & $71.8 \pm 1.18$ & $57.1 \pm 1.07$ & $* * *$ \\
Liveweight gain up to day 120 of gestation (g day $\left.{ }^{-1}\right)$ & $229 \pm 9.1$ & $105 \pm 3.9$ & $* * *$ \\
Body condition score at day 100 of gestation & $2.71 \pm 0.07$ & $2.14 \pm 0.08$ & \\
\hline
\end{tabular}

Values are mean $( \pm$ sEM).

$* * * P<0.001 ;$ ns: not significant.

higher $(P<0.001)$ in the RMG than in the NMG groups by day 35 of gestation and remained higher throughout pregnancy. Body condition score at day 100 of gestation was lower $(P<0.001)$ in the NMG than in the RMG groups and this difference was maintained during the final trimester for ewes delivering live young at term $(2.11 \pm 0.09$ and $2.69 \pm 0.10$ score units respectively, $P<0.001)$. Within the rapidly growing group, liveweight gain up to 120 days of gestation in ewes that subsequently aborted was equivalent to that of ewes delivering live young at term $(222 \pm 16.7$ and $234 \pm 11.3 \mathrm{~g} \mathrm{day}^{-1}$, respectively).

Rapid maternal growth rates during adolescent pregnancy were associated with a higher $(P<0.001)$ incidence of noninfectious spontaneous abortion than normally growing dams ( $25 \%$ versus $8.3 \%$ ). Four singleton fetuses, exhibiting various degrees of autolysis, were aborted by rapidly growing dams on days $121,121,123$ and 126 of gestation and weighed 218,498 , 1098 and $874 \mathrm{~g}$, respectively. In contrast, the fetus aborted on day 135 of gestation by a normally growing dam weighed $3600 \mathrm{~g}$ and was estimated to have died $<24 \mathrm{~h}$ before physical abortion.

For ewes delivering live young, complete placental records were obtained for all eight RMG and for eight of 11 .MG dams. For the RMG and NMG groups, respectively, placental mass at term (mean \pm SEM) was $263 \pm 16.8$ and $438 \pm 44.6 \mathrm{~g}$ $(P<0.002)$ while lamb birthweight was $2.74 \pm 0.25$ and $4.34 \pm 0.27 \mathrm{~kg}(P<0.001)$.

Duration of gestation for ewes delivering live young was shorter $(P<0.01)$ in the RMG than in the NMG group ( $140 \pm 0.94$ versus $143 \pm 0.28$ days). Birthweight was not related to the sex of the fetus and seven of 11 and five of eight live born lambs in the NMG and RMG groups, respectively, were female.

Concentrations of PSPB and progesterone for ewes delivering live young at term

Maternal PSPB was first detected (concentrations $>1.5 \mathrm{ng} \mathrm{ml}^{-1}$ ) in the maternal plasma at $23.8 \pm 0.95$ and $21.7 \pm 0.56$ days of gestation in RMG and NMG groups, respectively (Fig. 1). The biphasic pattern of PSPB secretion

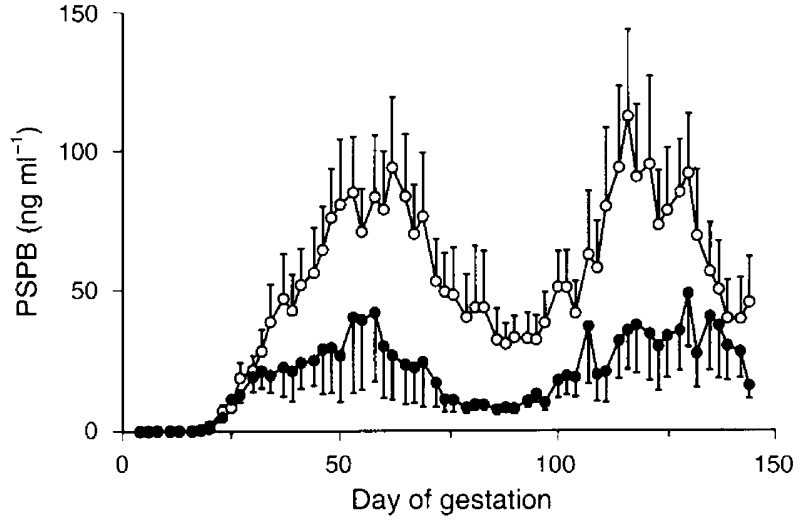

Fig. 1. Changes in maternal peripheral plasma pregnancy-specific protein $\mathrm{B}(\mathrm{PSPB})$ concentrations during gestation in rapidly growing $(\bullet, n=8)$ and normally growing $(, n=11)$ adolescent dams delivering live young at term. Samples were collected three times a week and values are means \pm SEM.

was similar in all animals but individual concentrations within treatment groups were highly variable (Figs 1 and 2). Overall mean PSPB concentrations were lower in RMG than in NMG ewes throughout gestation $(P<0.05)$, and the major statistical differences in relative terms were detected between day 50 and day 100 of gestation. Irrespective of treatment group, PSPB concentrations during this latter period were positively correlated with placental weight at term $(r=0.523, n=16, P<0.05)$ but not with lamb birthweight $(r=0.362, n=19, P>0.1)$. Within treatment groups, PSPB concentrations were not influenced by the sex of the fetus.

Mean peripheral progesterone concentrations throughout gestation were significantly lower $(P<0.02)$ in RMG compared with NMG ewes delivering live young at term (Fig. 3). Mean ovulation rate at the time of embryo transfer was not significantly different ( $1.9 \pm 0.35$ and $2.4 \pm 0.41$ corpora lutea in the RMG and NMG groups, respectively) and, irrespective of nutritional treatment, ovulation rate was not correlated with peripheral progesterone concentrations during the first half of gestation (days 5-70) when the corpus luteum is steroidogenically active $(r=-0.037)$. Maternal progesterone concentrations during the second half of gestation (days 73-135) are 


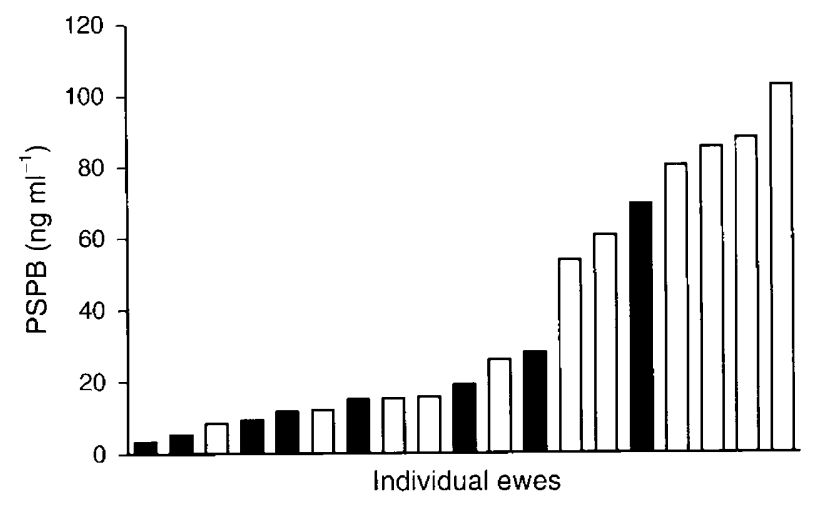

Fig. 2. Distribution of individual mean pregnancy-specific protein $B$ (PSPB) concentrations from days 18 to 135 of pregnancy in rapidly growing ( $\square$ ) and normally growing $(\subset)$ adolescent dams delivering live young at term.

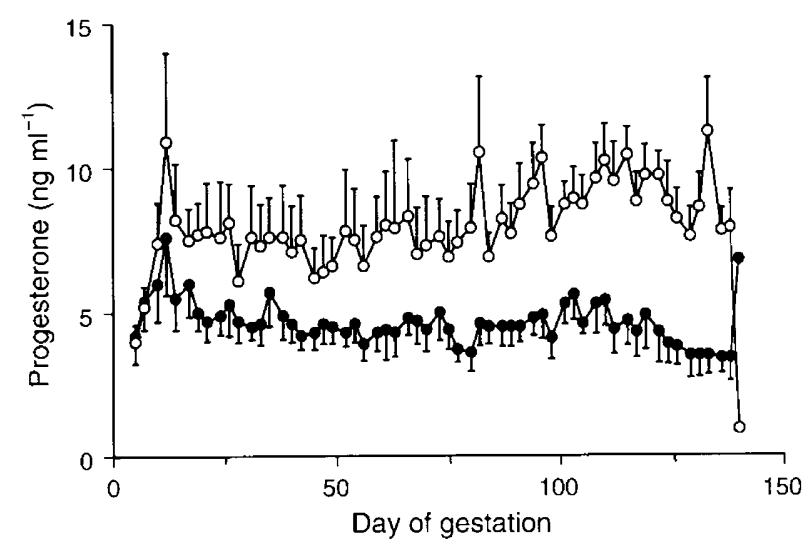

Fig. 3. Changes in maternal peripheral plasma progesterone concentrations during gestation in rapidly growing $(\bullet)$ and normally growing adolescent dams ( ) delivering live young at term. Samples were collected three times a week and values are means \pm SEM.

largely attributed to placental steroidogenesis and, irrespective of treatment group, were positively associated with both placental mass at term $(r=0.668, n=19, P<0.002)$ and lamb birthweight $(r=0.613, n=19, P<0.01)$. However, during the latter half of pregnancy mean peripheral progesterone concentrations were also inversely related to mean dry matter feed intakes $(r=-0.626, n=19, P<0.01)$.

Mean plasma concentrations of PSPB and progesterone were compared during the first, second and third trimesters. A positive association was detected between the two parameters between day 50 and day $101(r=0.717, n=19, P<0.001)$ and day 102 and 145 of gestation $(r=0.519, n=19, P<0.05)$.

\section{Concentrations of PSPB and progesterone for ewes that aborted}

Individual PSPB profiles for those ewes that aborted their fetuses in late gestation are illustrated (Fig. 4). Within the RMG group, PSPB secretion fell into two categories. Two ewes exhibited transient PSPB secretion between day 22 and day 70 and day 20 and day 90 of gestation, respectively (Fig. 4a, b). Thereafter, PSPB concentrations were largely undetectable for 20-50 days before physical abortion. In contrast, maternal

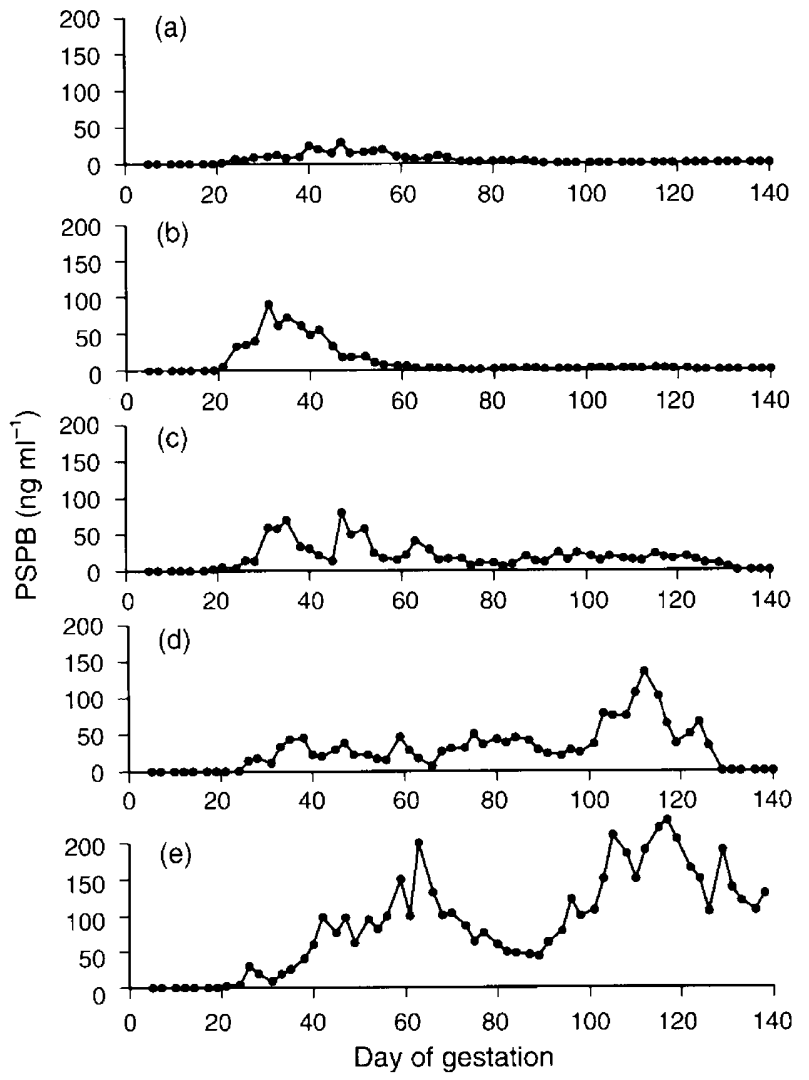

Fig. 4. Maternal peripheral plasma pregnancy-specific protein $B$ (PSPB) concentrations in rapidly growing $(a, b, c, d)$ and normally growing (e) adolescent dams which aborted singleton fetuses on days $121(\mathrm{a}, \mathrm{b}), 123$ (c), 126 (d) and 135 (e) of gestation.

progesterone concentrations remained high throughout both these pregnancies (data not shown) and only fell immediately before the fetal-placental unit was voided. The remaining two ewes that aborted within this group had variable but detectable PSPB concentrations up to the time of physical abortion (Fig. 4c, d). The NMG ewe that aborted had a biphasic PSPB profile indistinguishable from that of ewes delivering live young (Fig. 4e). Mean PSPB concentrations up to day 120 of gestation were highly correlated with the mass of the aborted fetus $(r=0.993, n=5, P<0.001)$. In all ewes that aborted, maternal progesterone concentrations up to the point of abortion were characteristic of normal pregnancies and were not significantly correlated with fetal mass $(r=0.557$, $n=5, P>0.1$ ).

\section{Discussion}

This study is the first to examine the relationship between peripheral PSPB concentrations in maternal plasma during gestation and placental mass at parturition. The nutritional treatments induced a highly significant difference in placental growth, with this being lower in the rapidly growing versus the normally growing adolescents; there was little overlap in the total placental masses at term. In addition, the use of embryo recovery and transfer procedures allowed us to study 
PSPB secretion in singleton pregnancies without the potentially confounding influence of partial embryo mortality at unknown time points during pregnancy. In this highly controlled experimental model, the positive association between PSPB concentrations during the period of rapid placental growth and placental mass at parturition implies that PSPB is released by the binucleate cells of the trophectoderm in concentrations proportional to placental mass. Previous studies in sheep have reported that PSPB concentrations in single blood samples collected between day 60 and day 120 of gestation were $78 \%$ accurate in differentiating between twin and singleton pregnancies (Willard et al., 1995). Total placental mass is higher in twin versus singleton pregnancies (Alexander, 1974) and hence the increased PSPB concentrations in the former category may be a direct reflection of higher placental mass. However, in the current study the individual variations in PSPB concentrations in singleton bearing ewes delivering live young at term were too high at all stages of gestation to advocate PSPB analysis as an individual biochemical marker of restricted placental growth.

In contrast, the significant correlation between PSPB concentrations and the mass of the fetus in ewes that aborted during late pregnancy suggests that sequential measurement of PSPB provides a reliable indication of severe fetal-placental distress in sheep. Abnormal PSPB profiles have also been observed in cows giving birth prematurely to stillborn calves (Dobson $e t a l$., 1993; Patel et al., 1995) and in human pregnancies the monitoring of pregnancy-specific glycoproteins provides routine prognostic indicators of fetal wellbeing (Ashwood, 1992). In the current study, sequential measurement of PSPB provided a much more accurate indicator of fetal viability than did progesterone. Two of four rapidly growing ewes with transient PSPB secretion during the first trimester had apparently normal progesterone concentrations until immediately before the autolysed fetus was aborted during late gestation. These PSPB profiles indicated that the pregnancies were in difficulty before any clinical signs of abortion and at a time when progesterone analysis failed to detect a potential problem. The maintenance of increased progesterone concentrations for some 20-50 days after PSPB concentrations were undetectable suggests that it may have been the corpus luteum that continued to secrete progesterone beyond its normal pregnancy lifespan rather than the placenta. Persistent corpus luteum function after a rapid decline in PSPB concentrations has also been observed in cattle inoculated with Actinomyces pyogenes to induce abortion during the first trimester (Semambo et al., 1992). Thus the presence of infection or the fetalplacental tissues themselves may have prolonged luteal function in the present study.

The biphasic pattern of PSPB secretion during pregnancy in the current study is consistent with previous reports, based on less frequent sampling regimens, in sheep (Ranilla et al., 1994) and in singleton bearing cattle (Patel et al., 1995). The first major peak in PSPB concentrations spanned the period of initial cotyledon formation and the most rapid phase of placental growth (days $30-75$ of gestation). As maximum cotyledonary size and placental mass is reached at about day $70-80$ of gestation in sheep (Kelly, 1992), the nadir in PSPB concentrations (days $75-100$ of gestation) occurred at a time when the growth of the placenta would largely have been complete. The biological function of PSPB is unresolved but the glycoprotein has identical sequence homology with PAG (Lynch et al. 1992) which has been classified as an inactive member of the aspartic proteinase family (Xie et al. 1991). Although unlikely to be enzymatically active as proteinases, the binding clefts of the molecules are probably conserved. Thus PSPB or PAG may still be capable of binding polypeptide growth factors and transporting them from the fetal to the maternal side of the placenta to enhance placental growth. The second major peak in PSPB concentrations occurred during the final trimester when the transport functions of the placenta have to increase severalfold to mediate rapid fetal growth (Bell, 1984). The increase in maternal PSPB concentrations during this period may simply occur as a consequence of the increase in fetal growth and may reflect enhanced fetal endocrine function or placental transport. It has also been suggested that the increase in PSPB or PAG at the end of gestation may be involved in remodelling of the placental attachments in preparation for the villi being pulled out of the maternal crypts after parturition (Zoli et al., 1992).

At first glance, the positive relationships between maternal progesterone concentrations during the second half of gestation and placental and fetal mass at term suggest that progesterone analysis may be used as a marker of placental growth and pregnancy outcome. However, maternal progesterone concentrations were also inversely related to dietary intake after the luteoplacental shift in progesterone secretion. High dietary intakes have been associated with low progesterone concentrations during early pregnancy in adult sheep (Williams and Cumming, 1982; Wallace et al., 1994) and have been attributed to an increase in blood flow through the gut and liver (Parr, 1992). As $96 \%$ of progesterone is metabolised during a single passage through these organs, the dietaryinduced increase in blood flow results in a reduction in peripheral progesterone concentrations. Thus, while progesterone synthesis and secretion may well have been reduced in the small placenta of the rapidly growing ewes, the lower maternal peripheral progesterone concentrations may also partially reflect dietary-induced alterations in progesterone metabolism. This conflict could be resolved by abruptly decreasing the dietary intakes of the rapidly growing dams in the final trimester when growth of the placenta has been completed.

The authors thank M. Franklin (BioSASS) for statistical advice, N. Jeanguyot and S. Germain (UNCEIA Service Techniques) for their assistance with the PSPB assays and R. G. Sasser (University of Idaho) for the oPSPB standard and antiserum. This work was supported by the Scottish Office Agriculture Environment and Fisheries Department.

\section{References}

Alexander G (1974) Birth weight of lambs: influences and consequences. In Size at Birth pp 215-245 Eds K Elliot and J Knight. Elsevier, Amsterdam

Ashwood ER (1992) Evaluating health and maturation of the unborn: the role of the clinical laboratory Clinical Chemistry 38 1523-1529

Bell AW (1984) Factors controlling placental and foetal growth and their effects on future production. In Reproduction in Sheep pp 144-152 Eds DR Lindsay and DT Pearce. Australian Academy of Science, Canberra

Djahanbahkch O, Swanston IA, Corrie JET and McNeilly AS (1981) Prediction of ovulation by progesterone Lancet ii 1164-1165 
Dobson H, Rowan TG, Kippax IS and Humblot P (1993) Assessment of fetal number, and fetal and placental viability throughout pregnancy in cattle Theriogenology 40 411-425

Humblot P, Camous S, Martal J, Charlery J, Jeanguyot N, Thibier M and Sasser RG (1988) Pregnancy-specific protein B, progesterone concentrations and embryonic mortality during early pregnancy in dairy cows Journal of Reproduction and Fertility $\mathbf{8 3}$ 215-223

Humblot P, De Montigny G, Jeanguyot N, Tetedoie F, Payen B, Thibier M and Sasser RG (1990) Pregnancy-specific protein B and progesterone concentrations in French Alpine goats throughout gestation Journal of Reproduction and Fertility 89 205-212

Kelly RW (1992) Nutrition and placental development Proceedings of the Nutrition Society of Australia 17 203-211

Lee CS, Wooding FBP and Brandon MR (1986) Immunogold co-localisation of ovine placental lactogen and the antibody recognised by the SBU-3 monoclonal antibody in sheep placental granules Journal of Reproduction and Fertility 78 653-662

Lynch RA, Alexander BM and Sasser RG (1992) The cloning and expression of the pregnancy-specific protein B (bPSPB) gene Biology of Reproduction 46 (Supplement 1) Abstract 73

Parr RA (1992) Nutrition-progesterone interactions during early pregnancy in sheep Reproduction Fertility and Development 4 297-300

Patel OV, Domeki I, Sasaki N, Takahashi T, Hirako M, Sasser RG and Humblot P (1995) Effect of fetal mass, number and stage of gestation on pregnancy specific protein B concentrations in the bovine Theriogenology 44 827-833

Ranilla MJ, Sulon J, Carro MD, Mantecon AR and Beckers JF (1994) Plasmatic profiles of pregnancy-associated glycoprotein and progesterone levels during gestation in Churra and Merino Sheep Theriogenology 42 537-545

Reimers TJ, Sasser RG and Ruder CA (1985) Production of pregnancy-specific protein by bovine binucleate trophoblastic cells Biology of Reproduction 32 (Supplement 1), Abstract 55

Ruder CA, Sasser RG, Dahmen J] and Stellflug JN (1988) Detection of pregnancy in sheep by radioimmunoassay of sera for pregnancy-specific protein $B$ Theriogenology 29 905-912

Russel AJF, Doney JM and Gunn RG (1969) Subjective assessment of body fat in live sheep Journal of Agricultural Science (Cambridge) 7245 I-454
Sasser RG, Ruder CA, Ivani KA, Butler JE and Hamilton WC (1986) Detection of pregnancy by radioimmunoassay of a novel pregnancy-specific protein in serum of cows and a profile of serum concentrations during gestation Biology of Reproduction 37 1307-1316

Semambo DKN, Eckersall PD, Sasser RG and Ayliffe TR (1992) Pregnancyspecific protein $B$ and progesterone in monitoring viability of the embryo in early pregnancy in the cow after experimental infection with Actinomyces pyogenes. Theriogenology $37741-748$

Vasques Ml, Horta AEM, Marques CC, Sasser RG and Humblot P (1995) Levels of $\mathrm{bPSPB}$ throughout single and twin pregnancies after $\mathrm{AI}$ or transfer of IVM/IVF cattle embryos Animal Reproduction Science 38 279-289

Wallace JM, Aitken RP and Cheyne MA (1994) Effect of post-ovulation nutritional status in ewes on early conceptus survival and growth in vivo and luteotrophic protein secretion in vitro Reproduction Fertility and Development 6 $253-259$

Wallace JM, Aitken RP and Cheyne MA (1996) Nutrient partitioning and fetal growth in rapidly growing adolescent ewes Journal of Reproduction and Fertility 107 183-190

Willard JM, White DR, Wesson CAR, Stellflug J and Sasser RG (1995) Detection of fetal twins in sheep using a radioimmunoassay for pregnancy-specific protein B Journal of Animal Science 73 960-966

Williams AH and Cumming IA (1982) Inverse relationship between concentration of progesterone and nutrition in ewes Journal of Agricultural Science (Cambridge) 98 5 17-522

Wood AK, Short RE, Darling A, Dusek GL, Sasser RG and Ruder CA (1986) Serum assays for detecting pregnancy in mule and white-tailed deer Journal of Wildife Manugement 50 684-687

Xie S, Low BG, Nagel RJ, Kramer KK, Anthony RV, Zoli AP, Beckers J and Roberts RM (1991) Identification of the major pregnancy-specific antigens of cattle and sheep as inactive members of the aspartic proteinase family Proceedings of the National Academy of Sciences USA $8810247-10251$

Zoli AP, Guilbault LA, Delahaut P, Ortiz WB and Beckers J (1992) Radioimmunoassay of a bovine pregnancy-associated glycoprotein in serum: its application for pregnancy diagnosis Biology of Reproduction 46 83-92 